\title{
Editorial
}

\section{A SAÚDE EM SEUS DIVERSOS NÍVEIS DE ATENÇÃo}

\author{
Divanise Suruagy Correia ${ }^{1}$
}

A saúde apresenta múltiplas facetas, não sendo apenas o estado de bom funcionamento do organismo humano, englobando aspectos multifatoriais, como o bem-estar físico, mental e social descrito em sua definição clássica, sendo acrescido, nos últimos anos, o aspecto espiritual. Estudar a saúde exige a consideração de vários níveis de assistência, bem como de prevenção.

A assistência primária é praticada nas unidades de atenção básica à saúde, porta de entrada do Sistema Único de Saúde (SUS), quando ocorrem os primeiros atendimentos, sendo orientadas as noções básicas para a promoção da saúde e prevenção de doenças. Por ela, inicia-se a organização do fluxo de serviços na rede de saúde, sendo palco da Estratégia da Saúde Família (ESF) no Brasil. A atenção secundária oferece os serviços especializados em níveis ambulatorial e hospitalar, como os procedimentos de média complexidade. $\mathrm{Na}$ ação terciária, encontram-se os procedimentos de alta complexidade, como o conjunto de terapias e procedimentos de elevada especialização, incluindo a alta tecnologia.

A atenção básica, como porta de entrada e assistência primária, deve assistir todas as faixas etárias. Ao se falar de mulheres grávidas, a atenção ao pré-natal deve avaliar o risco gravídico. O profissional médico deve ser capaz de avaliar a evolução da gravidez, identificando quando é necessário referenciar a gestante para níveis mais complexos de atenção. O artigo: "Pré-natal na Atenção Básica: conhecimentos médicos" aborda uma pesquisa realizada por médicos especialistas em Saúde da Família e que atuam na ESF em Alagoas.

Toda essa rede do SUS oferece assistência e atenção às mais diversas enfermidades e agravos, encontrando-se, nos últimos anos, os casos de doenças crônicas como hipertensão, diabetes e doenças degenerativas que se tornam problemas de saúde pública. Houve mudanças relacionadas aos hábitos alimentares que se refletem no aumento da prevalência do sobrepeso e

\footnotetext{
1 Professora associada da Faculdade de Medicina da Universidade Federal de Alagoas. Campus A. C. Simões. Av. Lourival Melo Mota, s/n. Tabuleiro dos Martins. 57072-900. Maceió - Al, Brasil. Email:divanisesuruagy@gmail.com
} 
obesidade, sendo esta última apontada, pela Organização Mundial de Saúde (OMS), como um dos maiores problemas de saúde pública no mundo. Levantamentos apontam para $50 \%$ da população acima do peso, levando a complicações de saúde agregadas ao excesso se peso, diretamente com Diabetes Mellitus tipo 2 e doença cardíaca isquêmica.

Sobrepeso e obesidade envolvem fatores biológicos individuais como, também, a integração de outros fatores econômicos, sociais e culturais. Dessa forma, aspectos como a dieta e a prática de exercícios devem ser analisados além da condição de trabalho, moradia e rede de abastecimento, no sentido de avaliar os modelos causais da doença.

Neste número, trazem-se dois artigos que estudam o tema obesidade: "Antibióticos nas fases iniciais da vida: um precursor da obesidade infantil" e o "Impacto de novas comorbidades na qualidade de vida de obesos pós-cirurgia bariátrica". O primeiro estuda os riscos em uma fase precoce da vida associados a um tipo de medicação que é usualmente utilizada. O segundo avalia a vida de pessoas submetidas à cirurgia bariátrica como tratamento da obesidade mórbida.

Na atenção terciária, são acompanhados os casos de câncer e, neste número, traz-se o artigo: "Diagnósticos de Enfermagem identificados em idosos atendidos em um serviço de radioterapia", que aborda o tema nesse nível de atenção em uma população bem vulnerável.

A educação na área da saúde deve englobar estratégias como a promoção da saúde entre grupos vulneráveis, como os usuários de drogas, sexualidade, além da atenção aos primeiros socorros. Temas que também são apresentados neste número.

Finalmente, apresenta-se a resenha crítica "Estranhos à nossa porta", que convida a um mergulho na obra de Zygmunt Bauman.

Que este número contribua para uma atualização nos temas apresentados e se transforme em bons momentos de leitura. 